\title{
Aplicação dos conceitos de modelagem e de redes de Petri na análise do processo produtivo da indústria sucroalcooleira ${ }^{(1)}$
}

\author{
Mamoru Carlos Yamada(2), Arthur José Vieira Porto(2) e Ricardo Yassushi Inamasu(3)
}

\begin{abstract}
Resumo - A modelagem, como meio de análise de processos do agronegócio, bem como de cadeias produtivas, atende à demanda por métodos apropriados. O presente trabalho objetivou avaliar a aderência dos conceitos de modelagem e de rede de Petri aplicados ao complexo agroindustrial da cana-deaçúcar. Utilizou-se uma empresa real para a aquisição das informações. Os modelos das cadeias de atividades foram validados com o uso da rede de Petri, por meio de um método de análise em que são simulados todos os caminhos possíveis e os estados que o sistema modelado pode atingir. O estudo resultou em 14 conjuntos de etapas de produção, englobando todas as operações unitárias das cadeias produtivas do açúcar e do álcool, desde o plantio da cana até o armazenamento do açúcar e do álcool.
\end{abstract}

Termos para indexação: açúcar, álcool, complexo agroindustrial, modelos de simulação.

\section{Application of modeling and Petri net concepts in the productive process of the sugarcane industry}

\begin{abstract}
The modeling, as a tool of analysis of agribusiness processes as well as of productive chains, supplies the demand for appropriated methodological tools. The present work aimed to evaluate the adherence of modeling and Petri net concepts applied to the sugarcane agroindustrial complex. A real company was used for the acquisition of the information. Models of the chains of activities were validated with the Petri net tool, through an analysis method where all possible paths and all states that the modeled system can reach are simulated. The study resulted in 14 groups of production stages, including all unitary operations of the sugar and alcohol productive chains, from the planting of the cane to the storage of the sugar and alcohol.
\end{abstract}

Index terms: sugar, alcohol, agroindustrial complex, simulation models.

\section{Introdução}

O setor sucroalcooleiro constitui o principal agronegócio brasileiro. Na safra 1999/2000 foram produzidas 315 milhões de toneladas de cana-de-açúcar, 20 milhões de toneladas de açúcar e 12,8 bilhões de litros de álcool (Agroindústria..., 2000), sendo o Estado de São Paulo responsável por 194 milhões de

(1) Aceito para publicação em 6 de setembro de 2001 . Extraído da dissertação de mestrado apresentada pelo primeiro autor à Universidade de São Paulo (USP), Escola de Engenharia de São Carlos (EESC).

(2) USP, EESC, Dep. de Engenharia Mecânica, Av. do Trabalhador Sãocarlense, 400, CEP 13566-590 São Carlos, SP. E-mail: mcyamada@sc.usp.br, ajvporto@sc.usp.br

(3) Embrapa-Centro Nacional de Pesquisa e Desenvolvimento de Instrumentação Agropecuária, Rua XV de Novembro, 1452, CEP 13560-970 São Carlos, SP. E-mail: ricardo@cnpdia.embrapa.br toneladas de cana-de-açúcar, 13,0 milhões de toneladas de açúcar e 8,5 bilhões de litros de álcool (União da Agroindústria Canavieira do Estado de São Paulo, 2001). Assim, o Brasil posiciona-se no cenário internacional como o maior produtor e exportador mundial de açúcar de cana e o maior produtor e consumidor de álcool (Saito, 2000); é também o único país a introduzir, em larga escala, o álcool como combustível alternativo ao petróleo.

Segundo Saito (2000), a indústria canavieira convive, no âmbito mundial, com as incertezas relativas às reservas mundiais de açúcar e de combustível, e, no âmbito nacional, com políticas protecionistas e diferenças regionais. No Brasil, o setor pode ser dividido em duas regiões (Waack et al., 1998): Norte/ Nordeste, voltada para a produção de açúcar para exportação; e Centro/Sul, voltada para a produção de álcool como alternativa energética. Com a liberação de mercado e o crescente aumento da eficácia produtiva, o Centro/Sul ultrapassou o Norte/Nordes- 
te nas exportações de açúcar, o que vem gerando um cenário de conflito entre as regiões.

O processo produtivo sucroalcooleiro é caracterizado pela sazonalidade: na época da safra, a usina trabalha com sua maior capacidade, e na entressafra, faz sua manutenção e gerencia seu estoque (Saito, 2000). Assim, torna-se inviável a tentativa de experiências muito inovadoras durante o período produtivo. Neste aspecto, a simulação vem sendo utilizada como apoio na busca de uma melhor compreensão do sistema sucroalcooleiro, sendo possível analisar opções de planejamento sem intervir no sistema produtivo real.

O Instituto Cubano de Investigaciones de los Derivados de la Caña de Azúcar desenvolveu um sistema computacional que permite a simulação dos processos tecnológicos da indústria açucareira e de derivados da cana, utilizando modelos determinísticos e estocásticos, assim como combinações de ambos (Esalq, 1992). Saito (2000) analisou o comportamento da cadeia agroindustrial do açúcar com o auxílio de simulação baseada em "System Dynamics", para identificar pontos de alavancagem. Hahn \& Ribeiro (1999) desenvolveram um simulador para o planejamento do transporte de cana, baseado em heurística (técnica que melhora a eficiência de um processo de busca de soluções, apontando para direções geralmente interessantes, mas que pode deixar de fora pontos de interesse para determinadas análises). Uma análise do processo de descarga de cana em usina, por meio de técnicas de simulação utilizando o software Arena, foi apresentada por Iannoni \& Morabito (2000). Delgado \& Cesar (1990) descreveram e equacionaram as etapas produtivas para a produção de açúcar, indicando cálculos e valores práticos para o funcionamento adequado dos equipamentos e processos de produção. Higgins et al. (1998) desenvolveram um modelo de otimização do fornecimento de cana, visando maximizar a produção de açúcar e a receita líquida em relação à data de colheita; Muchow et al. (1998) utilizaram o mesmo modelo para examinar o impacto do tipo e da idade da cultura sobre os mesmos parâmetros.

O processo de modelagem para análise de sistemas produtivos tem sido uma tarefa multidisciplinar, que vem exigindo o desenvolvimento de métodos de análise que possam refletir os vários níveis de abstração. Em geral, os instrumentos de modelagem e programação disponíveis possuem limitações (D’Souza \& Khator, 1994; Moore \& Gupta, 1996) para a representação de sistemas com características concorrentes ou paralelas (quando um ou mais eventos são independentes, ou seja, um ou mais podem ocorrer antes, depois ou ao mesmo tempo que outros), assíncronas (eventos podem ocorrer ou se repetir sem uma periodicidade), e distribuídas (o controle da ocorrência de eventos não é centralizada), entre outras.

A rede de Petri é uma técnica de modelagem matemática e gráfica aplicável em estudos de sistemas de processamento de informação com características concorrentes, assíncronas, distribuídas, paralelas, não determinísticas e estocásticas (Murata, 1989). Vem obtendo significativos avanços em áreas como matemática teórica, sistema de informação, automação industrial e outras áreas onde a rede de informação é complexa. A grande vantagem sobre outros meios de descrição gráfica é o seu formalismo matemático com um número grande de métodos de análise e adaptações para utilização em variados ambientes.

O objetivo deste trabalho foi avaliar o processo de modelagem e análise das cadeias produtivas do açúcar e do álcool, por meio da aplicação dos conceitos de rede de Petri.

\section{Material e Métodos}

A descrição e os modelos foram desenvolvidos a partir do levantamento de dados teóricos da bibliografia (Hugot, 1977; Delgado \& Cesar, 1990; Esalq, 1992) e de dados práticos coletados na Usina Santa Adélia, no Município de Jaboticabal, São Paulo.

A modelagem e a análise das propriedades dos modelos foram validadas no editor "Petri Net Tools" (Nakamura et al., 1997), desenvolvido pelo Laboratório de Simulação de Sistemas de Eventos Discretos, da Escola de Engenharia de São Carlos, da Universidade de São Paulo, em conjunto com a Embrapa-Centro Nacional de Pesquisa e Desenvolvimento de Instrumentação Agropecuária.

\section{Aplicações de rede de Petri}

Uma rede de Petri possui uma representação gráfica particular, constituída de dois tipos de elementos, chamados de lugares e transições, onde arcos saem de um lugar para uma transição ou de uma transição para um lugar. 
Um lugar pode ser utilizado como indicação de um estado (conjunto dos valores atuais dos parâmetros que definem um dado sistema, num dado instante) do sistema a ser modelado. É representado graficamente como um círculo e possui os seguintes atributos: identificação, marcas e capacidade. Uma marca é um inteiro não-negativo associado a cada lugar. A capacidade é o número máximo de marcas que o lugar pode suportar em algum tempo, e não é denotada para capacidade de valor infinito. Uma transição pode representar uma operação ou ação realizada pelo sistema. É representada graficamente como uma barra e possui os seguintes atributos: identificação e, para redes de Petri temporizadas, o tempo, que indica quanto tempo uma transição gasta no seu disparo. Um arco que sai de um lugar e chega a uma ou mais transições, juntamente com as marcações, indica as condições para que uma ação seja realizada. $\mathrm{O}$ arco que parte de uma transição e alcança um ou mais lugares, representa as funções que geram os estados após a execução de uma ação. É representado graficamente como um arco direcionado que conecta os elementos na rede de Petri. Tem somente um atributo: o peso. Um arco com peso $\mathrm{k}$, em que $\mathrm{k}$ é um número inteiro positivo, pode ser interpretado como um conjunto de $\mathrm{k}$ arcos paralelos. Os arcos com peso 1 podem usualmente ser omitidos.

Uma rede de Petri possui um estado inicial chamado de marcação inicial, $\mathrm{M}_{0}$. Uma marcação (estado) associa a cada lugar um número inteiro não-negativo. Assim, diz-se que um lugar p está marcado com $n$ marcas, e colocam-se $n$ pontos (marcas) nele. Uma marcação é denotada por M, um vetor com $m$ elementos, em que $m$ é o número total de lugares. $\mathrm{O}$ componente i-ésimo de $\mathrm{M}$, denotado por $\mathrm{M}\left(\mathrm{p}_{\mathrm{i}}\right)$, é o número de marcas no lugar $\mathrm{p}_{\mathrm{i}}$.

A simulação de uma rede de Petri ocorre de acordo com as suas regras de disparo, da seguinte forma: uma transição é considerada habilitada para disparo se houver um número de marcas nos lugares de entrada igual ou maior que os respectivos pesos de arco. Após o disparo, os lugares de entrada perdem marcas na quantidade equivalente aos pesos dos respectivos arcos e são introduzidas marcas nos lugares de saída (Figura 1).

A título de ilustração, descreve-se uma aplicação simplificada de insumo. Para a aplicação, há a necessidade de uma quantidade disponível de insumos e de uma máquina para aplicação. As máquinas podem estar disponíveis ou em manutenção. A manutenção é realizada a cada duas aplicações. São utilizadas duas máquinas que concorrem na utilização de insumo. Esta situação pode ser apresentada por meio de um simples modelo em rede de Petri (Figura 2). O modelo sofre o disparo da transição $\mathrm{t}_{1}$ (aplicar insumo com a máquina 1), por duas vezes consecutivas, passando da marcação $M_{0}=\left(\begin{array}{llllll}2 & 5 & 2 & 0 & 0 & 0\end{array}\right.$

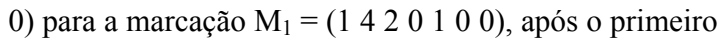
disparo, e da marcação, $M_{1}$ para a marcação $M_{2}=\left(\begin{array}{llll}0 & 3 & 2 & 0\end{array}\right.$ 200 ), após o segundo disparo. Nesse estado, a máquina 1 está disponível para o início de serviços de manutenção, e não mais disponível para uso na aplicação. Outra observação é na marcação, que representa a disponibilidade de insumos: no estado inicial, existem cinco marcas que, após duas aplicações, são reduzidas para três, restando, portanto, mais três aplicações até esgotarem-se os insumos. Evidentemente, não está incluída a aquisição de mais insumos, mas observa-se que isso é perfeitamente possível e depende da necessidade e finalidade do modelo.

Observa-se que outras seqüências de disparo são possíveis, visto que a transição $t_{4}$ encontra-se habilitada a partir da marcação inicial $\mathrm{M}_{0}$, além de outras transições tornarem-se habilitadas a partir do disparo de outras transições anteriores. A cada disparo, a rede de Petri alcança uma nova marcação. Por meio da árvore de cobertura (método de análise da rede de Petri que identifica todas as marcações que um modelo pode alcançar, a partir de uma dada marcação inicial), pode-se verificar todos os caminhos (seqüências de atividades) possíveis e todos os estados que o sistema modelado pode alcançar. Desta forma, se algum caminho desejado não pode ser percorrido, ou estado desejado não pode ser alcançado, o modelo deve ser revisado para satisfazer tal situação.

\section{Processo de desenvolvimento dos modelos das cadeias produtivas do sistema sucroalcooleiro}

A partir do conceito de cadeia de produção, sintetizado e sistematizado por Morvan (1988), citado por Batalha (1997), cujo enfoque de análise do sistema agroindustrial parte de seus produtos finais em direção à matéria-prima de base que os originaram, podem-se representar as cadeias agroindustriais do açúcar e do álcool por um arquétipo simplificado com três elos (Saito, 2000): insumo, representado por produtores rurais, cujo principal componente é a própria cana-de-açúcar; usinas, representadas por usinas de açúcar e álcool; e mercado, cujos agentes são representados por empresas de atacado e varejo. Este trabalho enfocou as etapas produtivas do elo usinas, e da interface insumo/usinas.

Assim, o processo produtivo sucroalcooleiro pode ser descrito como uma seqüência de operações unitárias agrícolas (interface insumo/usinas) e industriais (elo usinas) (Figura 3) (Yamada, 1999), que produz cana-de-açúcar, e da qual se obtêm, como produtos finais, o açúcar e o álcool, e inúmeros outros subprodutos, entre eles o bagaço e a vinhaça, reutilizados como insumos, no próprio desenvolvimento desse processo produtivo. 
Pela complexidade e elevado número de atividades e etapas envolvidas no processo produtivo sucroalcooleiro, inicialmente optou-se por dividi-lo em 14 etapas. De forma geral, a divisão procurou manter semelhanças com as divisões apresentadas por Hugot (1977), Delgado \& Cesar
(1990) e Esalq (1992), porém, foram incorporados os processos produtivos do setor agrícola e do elo entre o setor agrícola e o industrial (plantio, corte, carregamento, transporte, pesagem e amostragem), além da inclusão da etapa de tratamento de levedura. Em alguns casos, optou-se pela

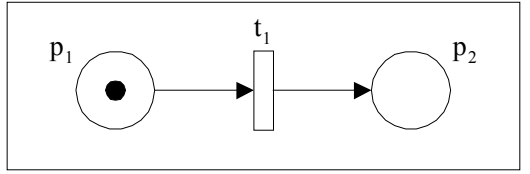

Após disparo de $t_{1}$

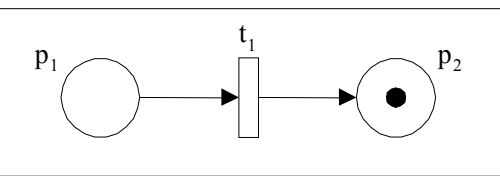

૫ Marcação em $\mathrm{p}_{1}$ é pré-condição de $\mathrm{t}_{1}$.

( Transição $t_{1}$ habilitada pela pré-condição.

$\checkmark$ Marcação inicial $M_{0}$ é (1 0$)$. Ou seja, $M\left(p_{1}\right)=1$ e $M\left(p_{2}\right)=0$.

( ) Marcação em $p_{1}$ é retirada, gerando pós-condição de $t_{1}$.

( Marcação $M_{1}$ após disparo de $t_{1}$ é $\left(\begin{array}{ll}0 & 1\end{array}\right)$. Ou seja, $M\left(p_{1}\right)=0$ e $\mathrm{M}\left(\mathrm{p}_{2}\right)=1$.
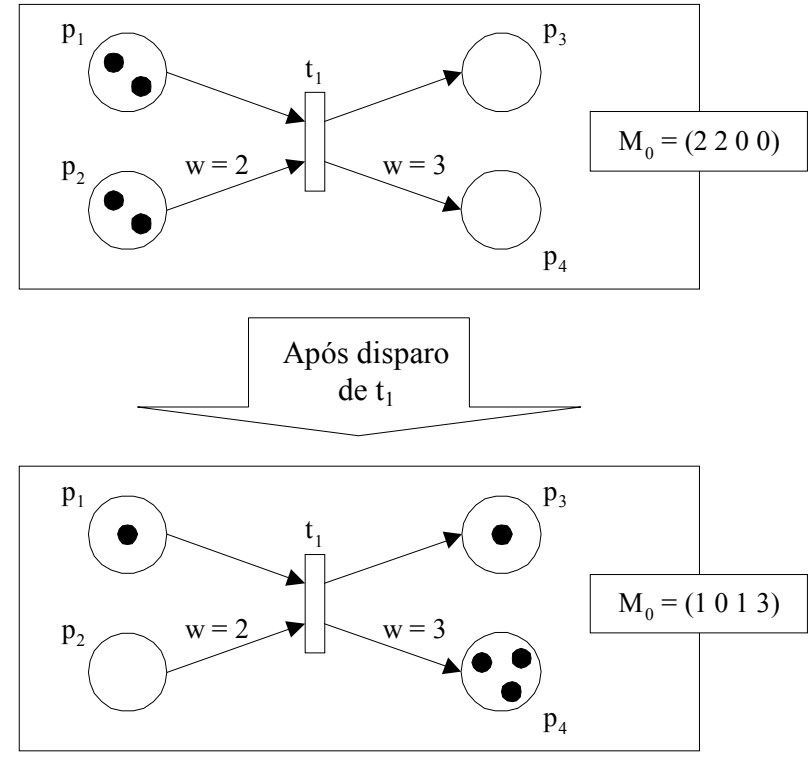

Legenda:

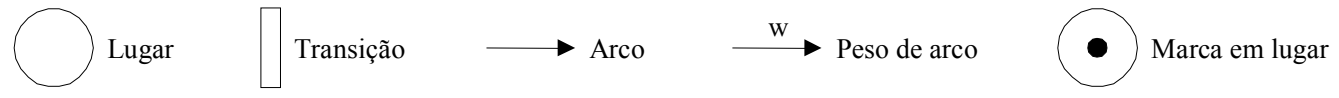

Figura 1. Dois exemplos de disparo de uma transição. 


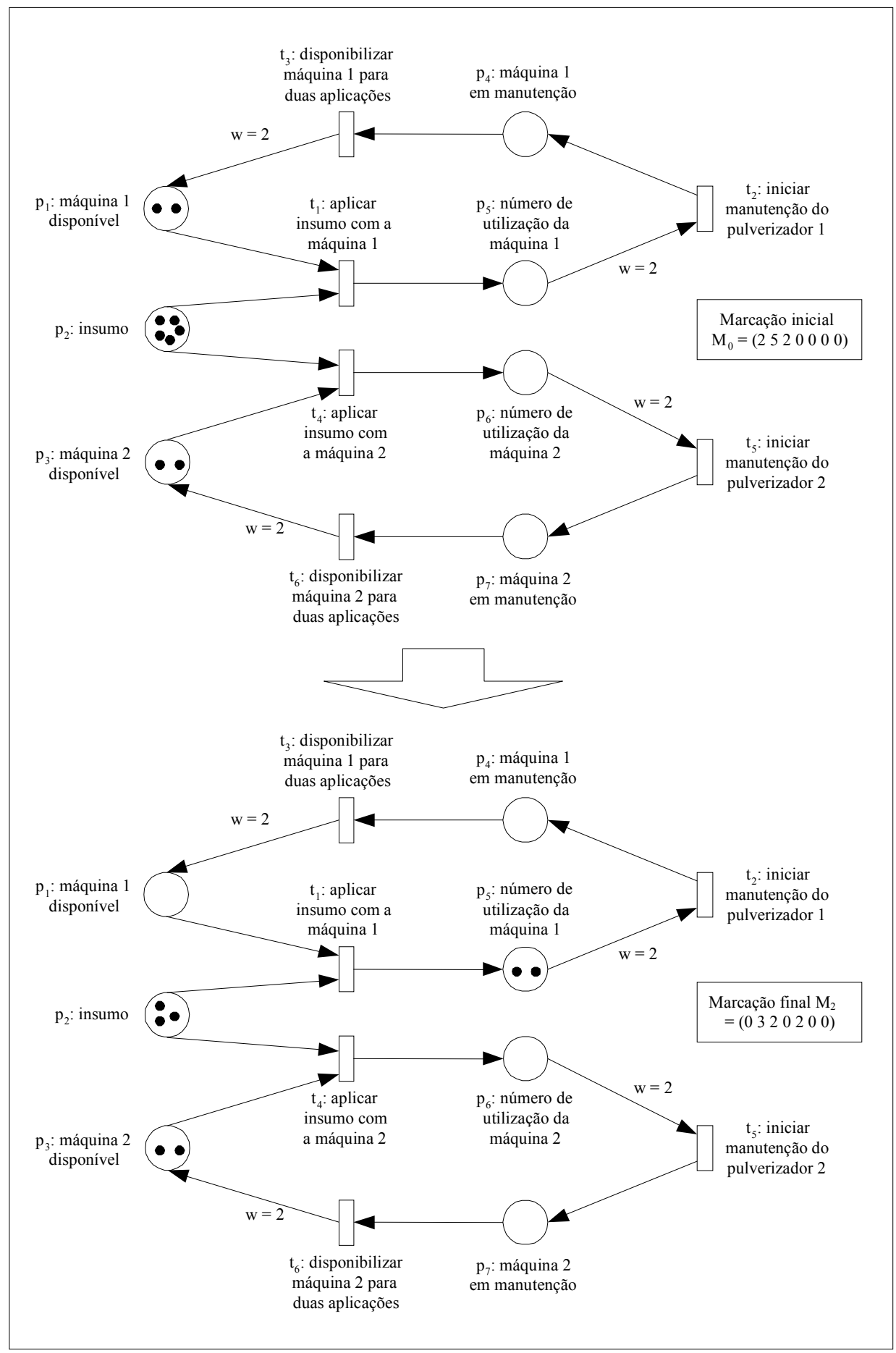

Figura 2. Modelo de aplicação de insumo, considerando concorrência no uso de insumos e controle de manutenção de máquinas. 
reorganização de etapas, para que os modelos correspondentes se tornassem menos complexos. O processo sucroalcooleiro, então, ficou dividido nas seguintes etapas e suas respectivas atividades: 1) Plantio: preparo e reforma do solo, plantio e crescimento do canavial; 2) Corte e carregamento: queima, movimentação de matéria-prima dentro do canavial e corte e carregamento de matéria-prima nas unidades de transporte; 3) Transporte, pesagem e amostragem: transporte de matéria-prima até a usina, e pesagem e amostragem dos veículos de transporte na entrada da usina; 4) Recepção de matéria-prima: descarga e movimentação de matéria-prima dentro da usina e alimentação de matéria-prima para a moagem; 5) Preparo da cana: preparo da cana para a moagem; 6) Extração: extração do caldo e embebição do bagaço; 7) Clarificação: sulfitação, aquecimento, decantação e filtração do caldo, para a fabri- cação de açúcar e de álcool; 8) Evaporação: evaporação do caldo para a fabricação de açúcar; 9) Fabricação de açúcar: cozimento da massa, cristalização e centrifugação do açúcar; 10) Fermentação: fermentação do caldo para fabricação de álcool; 11) Tratamento de levedura: tratamento, centrifugação e secagem da levedura utilizada na fermentação; 12) Destilação: destilação, retificação e desidratação do álcool; 13) Armazenamento: secagem, ensaque e armazenamento do açúcar; 14) Geração de vapor: geração de vapor a partir do bagaço.

Dentro desta divisão, podem-se destacar alguns trabalhos desenvolvidos para etapas específicas. Na interface entre o setor agrícola e o industrial, o Conselho dos Produtores de Cana-de-Açúcar, Açúcar e Álcool do Estado de São Paulo (1999) estabeleceu critérios para a avaliação da qualidade e para a remuneração da matéria-prima em fun-

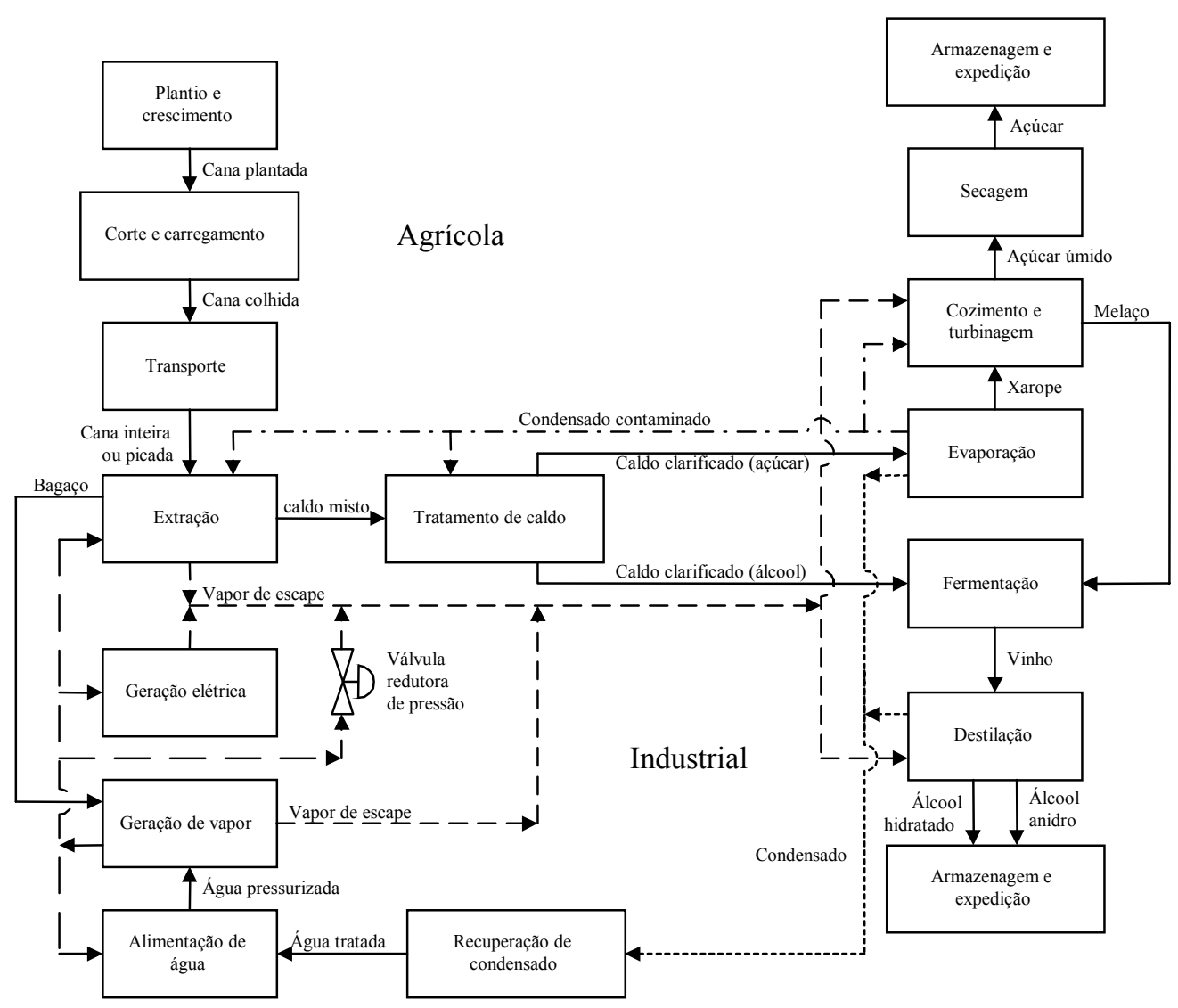

Figura 3. Diagrama do processo produtivo de uma usina sucroalcooleira (Yamada, 1999). 
ção da composição da produção de cada unidade industrial. Milan (1992) englobou as etapas de corte, carregamento e transporte em seu modelo físico representativo da produção de cana-de-açúcar para identificação de fatores críticos dos custos do processo de desenvolvimento da cana-de-açúcar e de estratégias para a redução desses custos. As etapas de plantio, corte, carregamento, transporte, pesagem, amostragem e recepção de matéria-prima, foram enfocados no trabalho de simulação computacional desenvolvido pela Cooperativa dos Produtores de Cana, Açúcar e Álcool do Estado de São Paulo (Braga, 1999). No setor de plantio, Keating et al. (1999) desenvolveram um módulo computacional (APSIM-Sugarcane) que simula o crescimento da cultura de cana-de-açúcar em função do clima, da disponibilidade de água e de nitrogênio; este módulo foi utilizado por Lisson et al. (2000) para analisar o desempenho do sistema, considerando-se a produção da cultura e questões relacionadas para dois sistemas contrastantes de produção, além de desenvolver diretrizes para questões metodológicas em simulações de longo prazo de sistemas produtivos açucareiros.

Inicialmente, para cada etapa realizou-se uma descrição das opções de atividades, apontando as possibilidades de produção, de forma genérica. Em seguida, fez-se um levantamento de dados, onde se particularizou a descrição da etapa analisada em função da organização estudada. Finalmente, foi desenvolvido o modelo descrito anteriormente. O processo de desenvolvimento dos modelos descrito foi utilizado em todas as 14 etapas. Como exemplo, apresenta-se o processo de desenvolvimento e o modelo gerado para a etapa denominada recepção de matéria-prima.

A recepção de matéria-prima na usina envolve as atividades de descarregamento das unidades de transporte e a movimentação da matéria-prima até o processo de extração. O descarregamento da matéria-prima, na forma de cana queimada ou crua, diferenciando-se ainda em cana inteira e picada, pode ser realizado: 1) em pátios a céu aberto, onde a matéria-prima é estocada na forma de cana inteira, para posterior suprimento das mesas alimentadoras; 2) em barracões cobertos, que possuem ao menos uma ponte rolante para movimentação da cana inteira; 3) diretamente nas mesas alimentadoras, em geral na forma de cana inteira; 4) diretamente nas esteiras transportadoras, na forma de cana inteira ou picada. Os equipamentos mais comumente utilizados são: 1) guincho, tipo Hilo, que retira a carga do veículo e efetua o seu tombamento por meio de um sistema de cabos e polias; 2) tombador hidráulico, que bascula a carroceria do veículo, fazendo a carga fluir diretamente para a esteira de alimentação de cana; 3) balança com pontes rolantes, para descarga de cana dentro do barracão. A cana descarregada deve ser conduzida à moagem de uma maneira uniforme e contínua. Essa interligação é feita por meio de: mesas alimentadoras, equipamentos transportadores que suportam o recebimento de uma carga completa das unidades de transporte de uma só vez, o que não é conveniente para uma esteira de cana; e esteiras transportadoras, que complementam o processo de alimentação de matéria-prima para a moagem.

O sistema analisado utiliza o armazenamento de matéria-prima em pátio (Figura 4). Os caminhões com matériaprima na forma de cana inteira podem ser descarregados de duas formas: 1) por um Hilo hidráulico na mesa alimentadora conjugada, que vai alimentar a esteira de cana 1 ; 2) por um Hilo hidráulico no pátio, para ser alimentada pelos tratores-empilhadoras na mesa alimentadora de $45^{\circ}$, que por sua vez, alimenta a esteira de cana 1 . O descarregamento no pátio é utilizado: 1) para diminuir a fila de veículos carregados que estão aguardando o descarregamento; 2) para formar estoque para o período em que não há corte de cana; 3 ) para liberar veículos quando há interrupção do processo industrial. A matéria-prima na forma de cana picada é descarregada na esteira de cana picada através de um tombador hidráulico. Caso haja necessidade, existe a possibilidade de se alimentar a esteira com os dois tipos de matéria-prima. Para isso, o veículo deve possuir basculamento lateral. Finalmente, a esteira de cana 1 e a esteira de cana picada alimentam a esteira de cana 2 que, por sua vez, envia a cana para o setor de preparo.

\section{Resultados e Discussão}

A análise de cobertura utilizada para validar os caminhos possíveis que o modelo pode seguir detectou as seqüências de disparo possíveis (Tabela 1). O modelo da etapa analisada apresenta quatro caminhos principais para a recepção de cana, representando os quatro tipos de descarregamento: de cana picada, de cana inteira no tombador hidráulico, na mesa conjugada e no pátio (Figura 5). A entrada principal do modelo é o lugar $\mathrm{p}_{1}$ (veículo no pátio). O caminho percorrido até o lugar $\mathrm{p}_{9}$ (veículo vazio na fila de pesagem) complementa o modelo do sistema de transporte, anterior ao modelo apresentado. A colocação de uma marca no lugar $\mathrm{p}_{26}$ (cana na esteira de cana 2) representa o início do processo industrial da matéria-prima. A simulação do modelo mostrou que, após o disparo das transições que representam cada um dos quatro tipos de descarregamento $\left(t_{4}, t_{8}, t_{12} e_{16}\right)$, ficam habilitadas a transição $t_{6}$ (deslocamento até fila de pesagem) e as demais seqüências de transições posteriores ao descarregamento, gerando paralelismo de atividades. Com isso, 
para o descarregamento de cana picada têm-se duas seqüências; para o descarregamento de cana inteira no tombador hidráulico, duas seqüências; para o descarregamento na mesa conjugada, três seqüências; e para o descarregamento no pátio, cinco seqüências. A multiplicidade de seqüências possíveis encontrados para um mesmo tipo de descarregamento ocorreu graças à utilização de uma rede de Petri sem o recurso da temporização (Murata, 1989; Desrochers \& Al-Jaar, 1994). Tal recurso agrega um tempo de duração às transições, o que gera uma única seqüência de disparo para cada caminho possível, consolidando, assim, a validação do modelo. Desta forma, a simulação deve apresentar somente um caminho para cada tipo de descarregamento, mantendo-se o paralelismo de atividades.

Neste modelo ocorre compartilhamento de recursos: 1) Tombador hidráulico $\left(\mathrm{p}_{4}\right)$, que deve estar disponível para o disparo das transições $t_{3}$ ou $t_{7}$ (deslocamento até tombador hidráulico); 2) Esteira de cana picada $\left(\mathrm{p}_{5}\right)$, que deve estar disponível para o disparo das transições $t_{4}$ ou $t_{8}$ (descarregamento com tombador hidráulico); 3 ) Esteira de cana 1 ( $\left.\mathrm{p}_{15}\right)$, que deve estar disponível para o disparo das transições $\mathrm{t}_{13}$ ou $\mathrm{t}_{17}$ (alimentação de cana inteira na esteira de cana 1$)$; 4) Esteira de cana $2\left(\mathrm{p}_{7}\right)$, que deve estar disponível para o disparo das transições $\mathrm{t}_{5}, \mathrm{t}_{14}$ ou $\mathrm{t}_{18}$ (alimentação de cana inteira na esteira de cana 2).

A utilização eficiente destes recursos traduz-se numa alimentação uniforme e constante de cana, o que é fundamental para o bom rendimento do processo industrial. Isto salienta outro aspecto importante do modelo: o sincronismo de atividades, isto é, uma determinada transição só deve ser disparada quando duas ou mais condições forem satisfeitas, por meio do disparo de transições anteriores. Várias marcas podem ser colocadas no lugar $\mathrm{p}_{1}$, representando a chegada de vários veículos carregados com matéria-prima. Dependendo do tipo de matéria-prima e da disponibilidade dos recursos: tombador hidráulico, Hilo do pátio e Hilo da mesa conjugada $\left(\mathrm{p}_{4}, \mathrm{p}_{19}\right.$ e $\mathrm{p}_{22}$ ), uma das seqüências acima é percorrida, o que resulta na colocação de uma marca no lugar $\mathrm{p}_{26}$. $\mathrm{O}$ aparecimento de mais de uma marca neste lugar num determinado instante durante a simulação indica a sobrecarga da esteira de cana 2 , que pode preju-

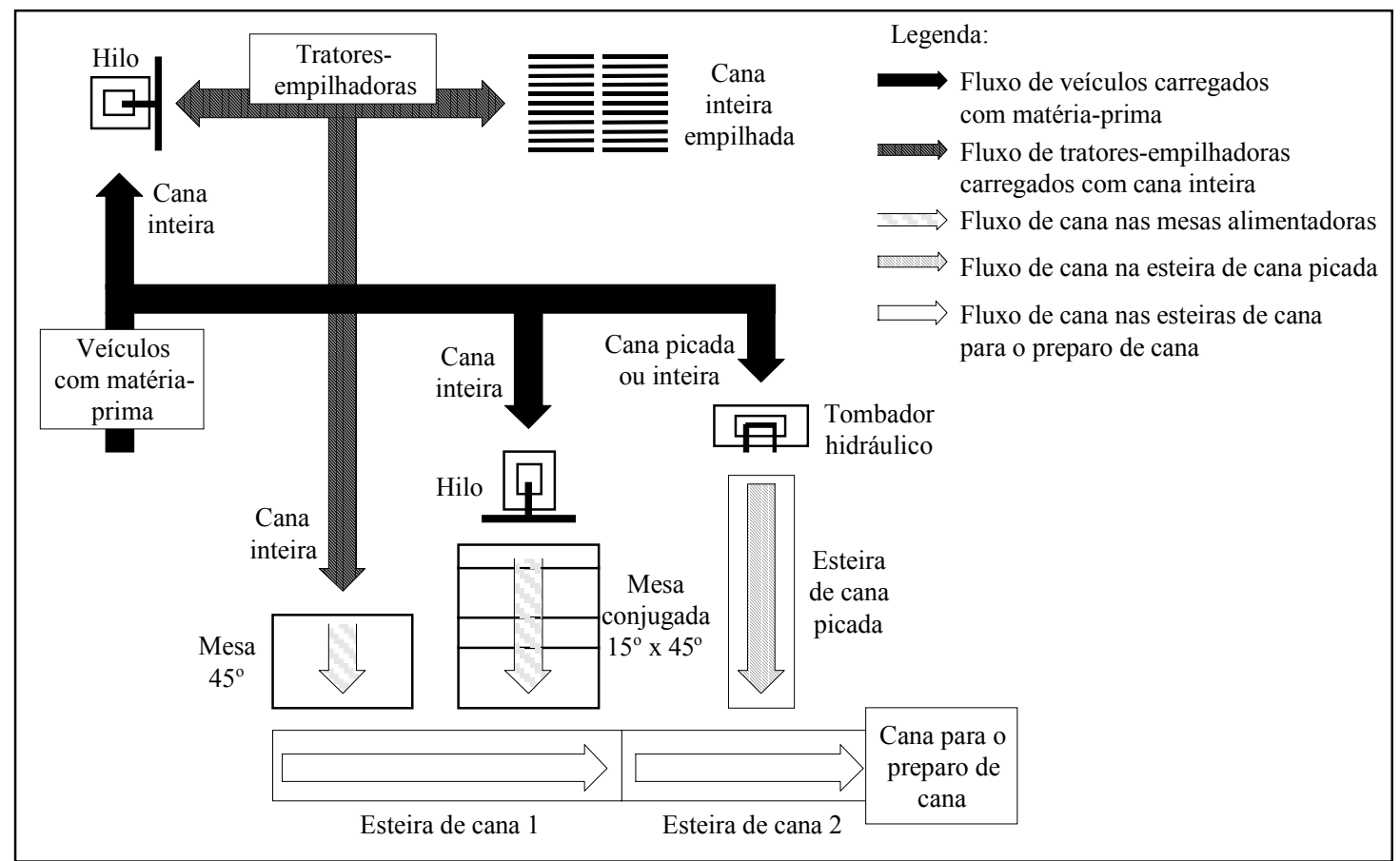

Figura 4. Diagrama do sistema de recepção de matéria-prima no pátio. 
dicar seu funcionamento e a alimentação de cana para a etapa seguinte de preparo. As seqüências de atividades devem, então, ser sincronizadas de forma a evitar esta situação.
O modelo identifica claramente, através de lugares, as principais variáveis que influenciam a etapa. No descarregamento as variáveis mais importantes são: tombador hidráulico $\left(\mathrm{p}_{4}\right)$, Hilo da mesa conjugada

Tabela 1. Seqüências de disparo possíveis para o modelo da recepção de cana.

\begin{tabular}{|c|c|}
\hline \multicolumn{2}{|c|}{ Seqüências de disparo } \\
\hline Seqüência 1 & Seqüência 2 \\
\hline Deslocamento até fila de cana picada & Deslocamento até fila de cana picada \\
\hline Deslocamento até tombador hidráulico & Deslocamento até tombador hidráulico \\
\hline Descarregamento com tombador hidráulico & Descarregamento com tombador hidráulico \\
\hline Alimentação de cana picada na esteira de cana 2 & Deslocamento até fila de pesagem \\
\hline Deslocamento até fila de pesagem & Alimentação de cana picada na esteira de cana 2 \\
\hline Seqüência 3 & Seqüência 4 \\
\hline Deslocamento até fila de cana inteira & Deslocamento até fila de cana inteira \\
\hline Deslocamento até tombador hidráulico & Deslocamento até tombador hidráulico \\
\hline Descarregamento com tombador hidráulico & Descarregamento com tombador hidráulico \\
\hline Alimentação de cana inteira na esteira de cana 2 & Deslocamento até fila de pesagem \\
\hline Deslocamento até fila de pesagem & Alimentação de cana inteira na esteira de cana 2 \\
\hline Seqüência 5 & Seqüência 6 \\
\hline Deslocamento até fila de cana inteira & Deslocamento até fila de cana inteira \\
\hline Deslocamento até Hilo da mesa conjugada & Deslocamento até Hilo da mesa conjugada \\
\hline Descarregamento com Hilo da mesa conjugada & Descarregamento com Hilo da mesa conjugada \\
\hline Alimentação de cana inteira na esteira de cana 1 & Alimentação de cana inteira na esteira de cana 1 \\
\hline Alimentação de cana inteira na esteira de cana 2 & Deslocamento até fila de pesagem \\
\hline Deslocamento até fila de pesagem & Alimentação de cana inteira na esteira de cana 2 \\
\hline Seqüência 7 & Seqüência 8 \\
\hline Deslocamento até fila de cana inteira & Deslocamento até fila de cana inteira \\
\hline Deslocamento até Hilo da mesa conjugada & Deslocamento até Hilo do pátio \\
\hline Descarregamento com Hilo da mesa conjugada & Descarregamento com Hilo do pátio \\
\hline Deslocamento até fila de pesagem & Armazenamento no pátio \\
\hline Alimentação de cana inteira na esteira de cana 1 & Alimentação de cana inteira na mesa $45^{\circ}$ \\
\hline Alimentação de cana inteira na esteira de cana 2 & Alimentação de cana inteira na esteira de cana 1 \\
\hline & Alimentação de cana inteira na esteira de cana 2 \\
\hline & Deslocamento até fila de pesagem \\
\hline Seqüência 9 & Seqüência 10 \\
\hline Deslocamento até fila de cana inteira & Deslocamento até fila de cana inteira \\
\hline Deslocamento até Hilo do pátio & Deslocamento até Hilo do pátio \\
\hline Descarregamento com Hilo do pátio & Descarregamento com Hilo do pátio \\
\hline Armazenamento no pátio & Armazenamento no pátio \\
\hline Alimentação de cana inteira na mesa $45^{\circ}$ & Alimentação de cana inteira na mesa $45^{\circ}$ \\
\hline Alimentação de cana inteira na esteira de cana 1 & Deslocamento até fila de pesagem \\
\hline Deslocamento até fila de pesagem & Alimentação de cana inteira na esteira de cana 1 \\
\hline Alimentação de cana inteira na esteira de cana 2 & Alimentação de cana inteira na esteira de cana 2 \\
\hline Seqüência 11 & Seqüência 12 \\
\hline Deslocamento até fila de cana inteira & Deslocamento até fila de cana inteira \\
\hline Deslocamento até Hilo do pátio & Deslocamento até Hilo do pátio \\
\hline Descarregamento com Hilo do pátio & Descarregamento com Hilo do pátio \\
\hline Armazenamento no pátio & Deslocamento até fila de pesagem \\
\hline Deslocamento até fila de pesagem & Armazenamento no pátio \\
\hline Alimentação de cana inteira na mesa $45^{\circ}$ & Alimentação de cana inteira na mesa $45^{\circ}$ \\
\hline Alimentação de cana inteira na esteira de cana 1 & Alimentação de cana inteira na esteira de cana 1 \\
\hline Alimentação de cana inteira na esteira de cana 2 & Alimentação de cana inteira na esteira de cana 2 \\
\hline
\end{tabular}




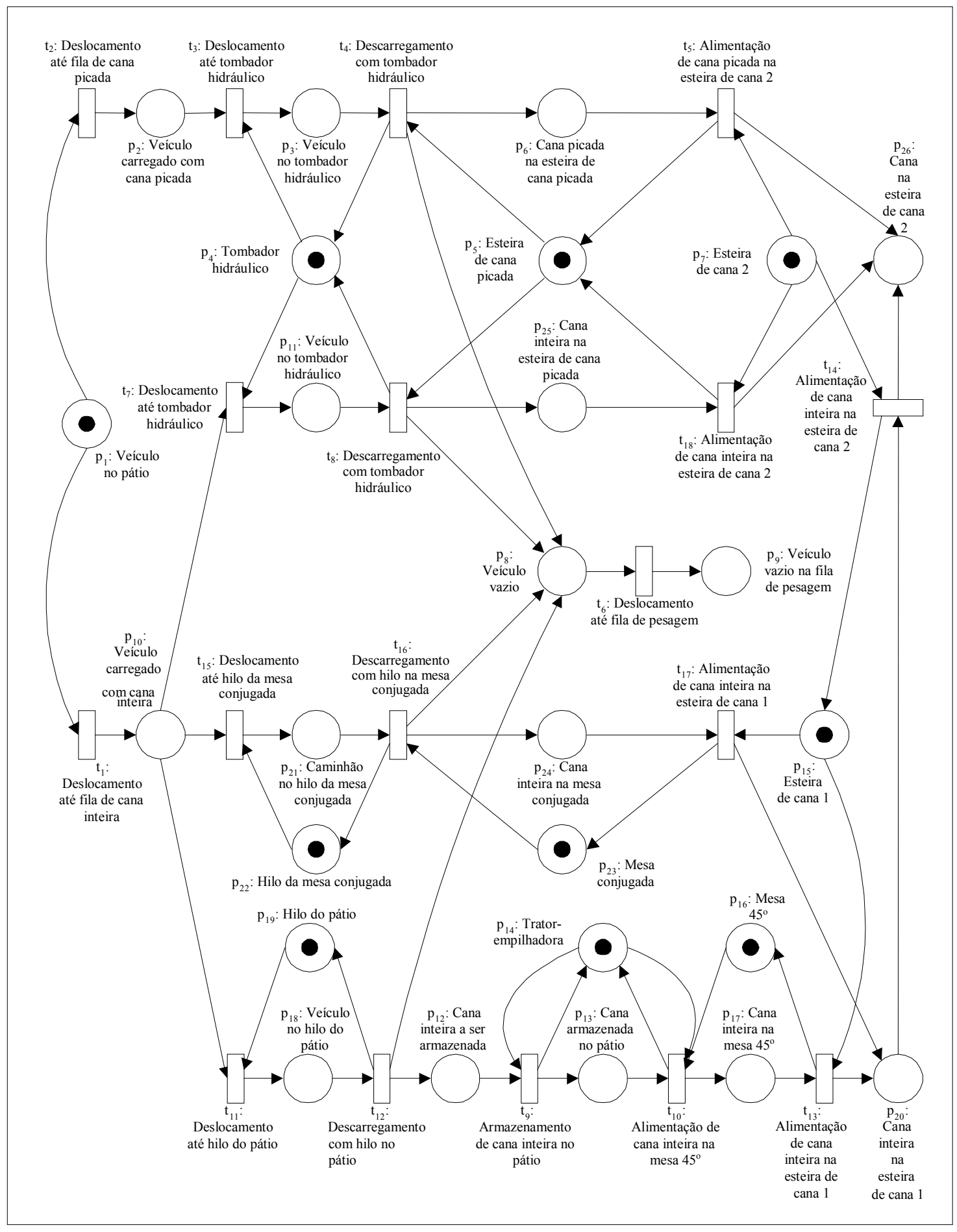

Figura 5. Modelagem do sistema de recepção de matéria-prima no pátio. 
$\left(\mathrm{p}_{22}\right)$ e o Hilo do pátio $\left(\mathrm{p}_{19}\right)$, sendo seus atributos principais: quantidade, tempo de descarregamento, freqüência e tempo de manutenção. Na movimentação, as variáveis principais são: 1$)$ veículo ( $\mathrm{p}_{2}$, $\mathrm{p}_{10}$ ), com os atributos: tempo de deslocamento até o local de descarregamento, freqüência de chegada na área de recepção e velocidade de deslocamento; 2) trator-empilhadora $\left(\mathrm{p}_{14}\right)$, cujos atributos importantes são: quantidade, tempos de deslocamento nas operações de armazenagem de cana no pátio e de alimentação de cana na mesa de $45^{\circ}$, freqüência e tempo de manutenção e abastecimento, custo de manutenção e abastecimento, velocidade de deslocamento nas diversas operações. Na alimentação, as variáveis principais são: 1) mesa alimentadora de $45^{\circ}$ $\left(\mathrm{p}_{16}\right)$ e mesa alimentadora conjugada $\left(\mathrm{p}_{14}\right)$, o que influi diretamente na capacidade de abastecimento, sendo os atributos principais: velocidade de alimentação de cana para a esteira, freqüência e tempo de manutenção e custo de manutenção; 2) esteira de cana picada $\left(\mathrm{p}_{5}\right)$, esteira de cana $1\left(\mathrm{p}_{15}\right)$ e esteira de cana $2\left(\mathrm{p}_{7}\right)$, com os atributos: velocidade de deslocamento da cana, capacidade de carga, freqüência e tempo de manutenção e custo de manutenção, sendo possível estimar tais atributos usando-se o valor da área de mesa requerida pela quantidade de cana necessária por unidade de tempo. Apesar de mostrar as variáveis do sistema, o modelo não permite caracterizar seus atributos, o que pode ser realizado com a utilização do recurso da temporização, que possibilita a inclusão das características determinísticas e estocásticas dos atributos (Murata, 1989; Desrochers \& Al-Jaar, 1994).

Outro aspecto importante a ser observado é a integração dos modelos. A simulação isolada de cada modelo foi executada com baixo grau de complexidade e apresentação de fácil compreensão, simplificando a análise. Porém, as ferramentas baseadas em rede de Petri existentes atualmente (University of Aarhus, 2000) carecem de funcionalidades que permitam a integração dos diversos modelos, de tal forma a possibilitar a análise sistêmica.

\section{Conclusões}

1. A rede de Petri permite boa visualização e acompanhamento da dinâmica e dos interrelacionamentos das atividades produtivas nas áreas de plantio, corte e carregamento, transporte, pesagem e amostragem, e recepção de cana, que possuem características predominantemente discretas.

2. Para objetos de natureza híbrida, com forte influência humana, como as áreas de preparo de cana, extração, clarificação, evaporação, fabricação de açúcar, tratamento de levedura, destilação e geração de vapor, e biológica, como as áreas de fermentação e armazenamento, a rede de Petri pode representá-los de forma global, inserida no contexto de sistemas discretos.

\section{Agradecimentos}

À Usina Santa Adélia S.A., do Município de Jaboticabal, SP, pelo fornecimento dos dados necessários para a descrição e modelagem das cadeias de produção apresentadas; ao Laboratório de Simulação de Sistemas de Eventos Discretos, da Escola de Engenharia de São Carlos, da Universidade de São Paulo, pelo desenvolvimento do editor "Petri Net Tools", que possibilitou a concretização dos resultados obtidos; à agência de fomento Fapesp, pelo apoio e financiamento do projeto de pesquisa.

\section{Referências}

AGROINDÚSTRIA canavieira do Brasil: um mercado de 12,7 bilhões. Jornalcana, Ribeirão Preto, abr. 2000. Disponível em: <http://www.jornalcana.com.br/ Numeros.htm>. Acesso em: 27 abr. 2000.

BATALHA, M. O. Sistemas agroindustriais: definições e correntes metodológicas. In: (Coord.). Gestão agroindustrial. São Paulo: Atlas, 1997. v. 1, p. 23-48.

BRAGA, J. Copersucar reduz custos com simulação. Revista Tecnologística, São Paulo, v. 4, n. 39, p. 16-23, fev. 1999.

CONSELHO DOS PRODUTORES DE CANA-DEAÇÚCAR, AÇÚCAR E ÁlCOOL DO ESTADO DE SÃO PAULO (São Paulo, SP). Manual de instruções. São Paulo, 1999. Disponível em: <http:// www.orplana.com.br/manual.htm>. Acesso em: 23 mar. 2001.

DELGADO, A. A.; CESAR, M. A. A. Elementos de tecnologia e engenharia do açúcar de cana. Piracicaba: Esalq, 1990. 1061 p. (Publicação, 54354). 
DESROCHERS, A. A.; AL-JAAR, R. Y. Applications of Petri nets in manufacturing systems: modeling, control, and performance analysis. New York: IEEE Press, 1994. p. $135-158$.

D'SOUZA, K. A.; KHATOR, S. K. A survey of Petri net applications in modeling controls for automated manufacturing systems. Computers in Industry, Amsterdam, v. 24, n. 1, p. 5-16, May 1994.

ESALQ (Piracicaba, SP). Curso de modelagem e simulação de processos na produção de açúcar, álcool e derivados. Piracicaba, 1992. 213 p. (Publicação interna, 56932).

HAHN, M. H.; RIBEIRO, R. V. Heuristic guided simulator for the operational planning of the transport of sugar cane. Journal of the Operational Research Society, Basingstoke, v. 50, n. 5, p. 451-459, May 1999.

HIGGINS, A. J.; MUCHOW, R. C.; RUDD, A. V.; FORD, A. W. Optimizing harvest date in sugar production: a case study for the Mossman mill region in Australia I. Development of operations research model and solution. Field Crops Research, Amsterdam, v. 57, n. 2, p. $153-$ 162, May 1998.

HUGOT, E. Manual de engenharia açucareira. São Paulo: Mestre Jou, 1977. 2 v.

IANNONI, A. P.; MORABITO, R. Análise do sistema logístico de descarga de cana inteira e picada em uma usina de cana-de-açúcar. In: ENCONTRO NACIONAL DE ENGENHARIA DE PRODUÇÃO, 20., 2000, São Paulo. Anais... São Paulo: Quattri Design, 2000. 1 CD.

KEATING, B. A.; ROBERTSON, M. J.; MUCHOW, R. C.; HUTH, N. I. Modeling sugarcane production systems I. Development and performance of the sugarcane module. Field Crops Research, Amsterdam, v. 61, n.3, p. 253-271, May 1999.

LISSON, S. N.; ROBERTSON, M. J.; KEATING, B. A.; MACHO, R. C. Modeling sugarcane production systems II. Analysis of system performance and methodology issues. Field Crops Research, Amsterdam, v. 8 , n. 1, p. 31-48, Sept. 2000.

MILAN, M. Improving operational management of harvest, transport and mechanization for sugar cane in Brazil. 1992. 226 p. Thesis (Ph.D.) - Cranfield Institute of Technology, Silsoe.
MOORE, K. E.; GUPTA, S. M. Petri net models of flexible and automated manufacturing systems: a survey. International Journal of Operational Research, London, v. 34, n. 11, p. 3001-3035, Nov. 1996.

MUCHOW, R. C.; HIGGINS, A. J.; RUDD, A. V.; FORD, A. W. Optimizing harvest date in sugar production: a case study for the Mossman mill region in Australia II. Sensitivity to crop age and crop class distribution. Field Crops Research, Amsterdam, v. 57, n. 3, p. 243-251, June 1998.

MURATA, T. Petri nets: properties, analysis and applications. Proceedings of the IEEE, New York, v. 77, n. 4, p. 541-580, Apr. 1989.

NAKAMURA, E. K.; FERREIRA, M. E.; INAMASU, R. Y.; KATO, E. R. R.; PORTO, A. J. V. Surge o Petri net tools: um editor de rede de Petri para modelagem de FMS. Máquinas e Metais, São Paulo, v. 32, n. 378, p. 101-110, jul. 1997.

SAITO, J. R. Análise das cadeias agroindustriais utilizando simulação computacional baseada na metodologia System Dynamics: um estudo de caso. 2000. 83 f. Dissertação (Mestrado) - Universidade Federal de São Carlos, São Carlos.

UNIÃO DA AGROINDÚSTRIA CANAVIEIRA DO ESTADO DE SÃO PAULO. Safra 00/01: mais álcool na menor safra da década. Informação UNICA, São Paulo, v. 4, n. 39, p. 1-8, jan./fev. 2001.

UNIVERSITY OF AARHUS. Department of Computer Science. Complete overview of Petri net tools database. Aarhus: DAIMI, 1997. Disponível em: <http:// www.daimi.au.dk/PetriNets/tools/complete_db.html $>$. Acesso em: 15 jul. 2000.

WAACK, R. S.; NEVES, M. F.; MORAES, S.; MARINO, M. K.; MAMONE, A.; SZASZ, A. H. Competitividade do sistema agroindustrial da cana-de-açúcar. In: FARINA, E. M. M. Q.; ZYLBERSZTAJN, D. (Coord.). Competitividade no agribusiness brasileiro: versão final. São Paulo: Instituto de Pesquisa Econômica Aplicada/USP, 1998. v. 5, p. 1-194. Disponível em: $<$ http:www.fea.usp.br/Fia/pensa/pdf/acucar.pdf $>$. Acesso em: 15 out. 2001.

YAMADA, M. C. Modelagem das cadeias produtivas da indústria sucroalcooleira visando a aplicação em estudos de simulação. 1999. 164 f. Dissertação (Mestrado) - Escola de Engenharia de São Carlos, Universidade de São Paulo, São Carlos. 